\title{
THE COMPARISON OF FEMORAL COMPONENT ROTATION IN THE TOTAL KNEE ARTHROPLASTY
}

\author{
Chmurny M, Krivanek S, Melisik M, Rovnak M, Necas L. \\ Orthopedic Clinic, Jessenius Faculty of Medicine in Martin, Comenius University and University \\ Hospital in Martin, Slovak Republic
}

\begin{abstract}
Introduction Background: Optimal femoral component rotation in total knee arthroplasty (TKA) is crucial to establish a balanced knee reconstruction. Unbalanced knees can lead to instability, patellofemoral problems, persistent pain, stiffness, and generally poorer outcomes including early failure. There are several methods to achieve the femoral component rotation such as balanced gap technique, measured resection technique, and bone landmarks such as transepicondylar line (TEA) and Whiteside line. The purpose of this study was to compare the balanced gap technique with the TEA technique.

Materials and Methods: This randomised prospective study compares the femoral component rotation obtained with the use of balanced gap technique and the TEA, as well as compares the differences due to preoperative knee desaxations. The study includes 50 knees, 19 with neutral alignment, 22 with varus, and 9 with valgus desaxation. The femoral component rotation was measured postoperatively on photodocumentation taken after determining the TEA and balanced gap technique line peroperatively. These lines were compared to the posterior femoral condyles obtaining the degree of rotation. In case of transepicondylar line it is condylar twist angle (CTA) and in case of ligament balancer rotation axis it is ligament balancer angle (LBA).

Results:The statistically significant differences in femoral component rotation using the techniques mentioned above as well as differences in individual knee desaxations were observed. The average LBA was 3.42 degrees and average CTA 3.58 in neutral knees group,but in the varus knees the average CTA value was 2.27 degrees and LBA value was 1.05 degrees. The average CTA value in patients with valgus desaxation is 4.78 degrees and LBA value is 5.22 degrees. According to Tukey Post Hoc test a statistically significant difference in LBA value is between neutral and varus knees with a significance level of $p=0.000022$ and the most significant difference between varus and valgus knees with a significance level of $\mathrm{p}=0.000011$.
\end{abstract}

Conclusion: The statistically significant differences in femoral component rotation using the techniques mentioned above as well as differences in individual knee desaxations were observed.

Keywords: Transepicondylar axis, balanced gap technique, rotational alignment.

\section{INTRODUCTION}

The correct femoral component rotation in the total knee arthroplasty is currently still discussed. Reaching the optimal rotation is crucial to create symmetric and well-balanced flection gap and adequate patellar tracking $(1,2,3,4,5,6,7,8,9,10)$.

Malrotation can lead to patellar subluxation, dislocation, patellar component loosening, and patellar fracture $(2,11)$. Malrotation can cause asymmetric overload and accelerate wearing and loosening of tibial component (12).

There are several methods of determination of femoral component rotation. Mostly bony landmarks such as transepicondylar line, Whiteside line, dorsal femoral condyles, and balanced gap technique are used (13). 
The purpose of this study was to compare the rotation of femoral component determined by the balanced gap technique with the transepicondylar line.

The aim of the study was also the relation of femoral component rotation and preoperative knee desaxation. Krackow and Mihalko reported that soft tissue release in extension affects also the flection gap (14). Medial soft tissue release in varus knees can lead to excessive extrarotation of distal femur by applying of ligament balacer in flection and intrarotation of femoral component relative to transepicondylar line. On the other hand, in valgus desaxation with lateral soft tissue release we assume intrarotation of the distal femur with extrarotation of the femoral component to transepicondylar axis $(13,15)$.

\section{METHODS}

In this prospective randomized study 50 knees of 46 patients, aged 57-81 years, in average 68 years, were examined. The group consisted of 29 women and 17 men who underwent implantation of unilateral or bilateral total knee arthroplasty in which CR Sigma prosthesis was implanted. From this sample 19 knees had physiological axis of the lower limb, 22 knees were with varus desaxation from 3-15 degrees, 7.95 degrees in average, and 9 knees had valgus desaxation from 5-15 degrees, 9 degrees in average. In order to avoid individual differences in surgical technique the surgeries in all patients were performed by the same surgeon.

From the study were excluded the patients with lesion of the posterior cruciate ligament, flection contracture greater than 20 degrees, varus or valgus knee desaxation greater than 20 degrees, patients who underwent osteotomy or surgery of knee soft tissues, and the patients with varus or valgus tibial component malposition verified post-operatively by $\mathrm{x}$-ray from the reason of adverse effect of malposition to femoral component rotation, which can be caused by use of ligament balancer.

The patients underwent spinal or general anaesthesia and mid-vastus approach without patella eversion and tournicet cuff with $300 \mathrm{mmHg}$ was applied.

After meniscectomy and resection of the anterior cruciate ligament a partial hoffectomy, in which a part of Hoff body is maintained as a prevention of adverse contact between ligamentum patellae and femoral component, was carried out. In the patella and femur, prominent osteophytes are resected and preliminary loosening of the soft tissues depending on pre-operative desaxation of the knee is performed. In case of valgus desaxation the tractus iliotibialis is cut by a transverse cut in the level of joint aperture from the extra-articular aspect. The distal femur is usually resected with 6 degrees valgus cut of $9 \mathrm{~mm}$ in depth. In flection knee contracture, if necessary, depth of resection may be increased according to the finding but it is important to avoid knee line elevation. After distal femoral resection transepicondylar and Whiteside lines were determined. Then, proximal tibia is resected perpendicularly to its anatomical axis with dorsal slope of 3 degrees. After these resections, in the knee extension, the ligament balancer is introduced by applying the same tension in the lateral and medial compartment. In our case it is the boundary of the level B and $\mathrm{C}$ at the bottom scale in which A equals the value of tension $63 \mathrm{~N}, \mathrm{~B}$ is $99 \mathrm{~N}$, and C is $135 \mathrm{~N}$. It can be assumed that in symmetrically balanced soft tissues the width of the extension gap should be the same in its medial and lateral part, which can be confirmed in the upper scales of the balancer. In the case of discrepancy an additional release of the soft tissues is necessary. After reaching the extension gap symmetry the ligament balancer is applied in the 90 degrees knee flexion, the same tension in medial and lateral compartment is used (it means the boundary of $\mathrm{B}$ and $\mathrm{C}$ levels at the bottom scale) while the femur rotates according to tension of the soft tissues of both compartments. This determines femoral component rotation and symmetry of flection gap is maintained.

Peroperative findings of the transepicondylar line and femoral component rotation axis determined by ligament balancer were collected by photodocumentation. Postoperatively 
the axes were compared with the line of dorsal femoral condyles by measuring the particular angles. In the case of transepicondylar line we can talk about condylar twist angle (CTA) and in the case of ligament balancer rotation axis about ligament balancer angle (LBA) (Fig. 1). The results were assessed and processed statistically.

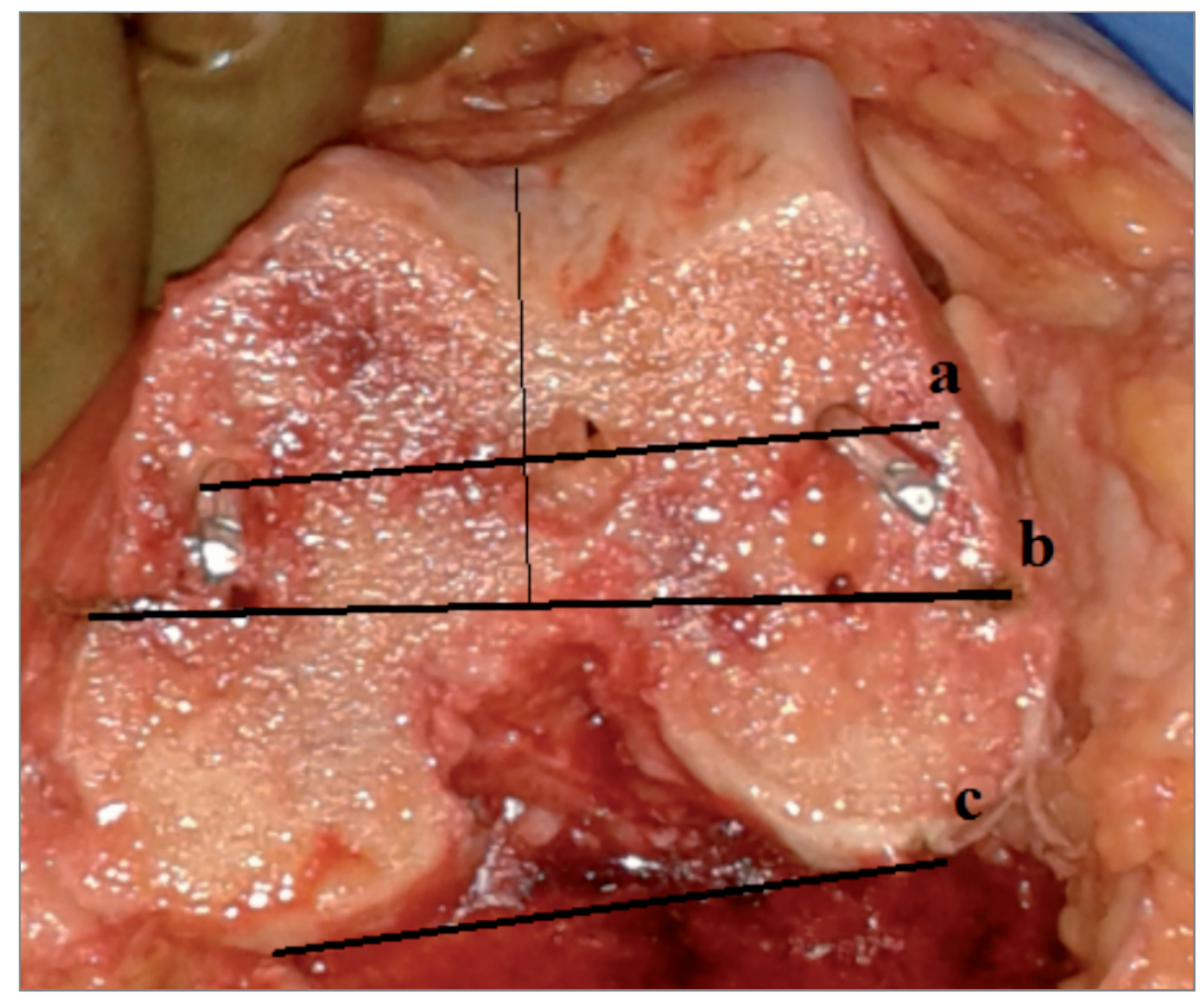

Fig. 1 a - ligament balancer rotation line, b - transepicondylar line, c-posterior femoral condyles line

\section{RESULTS}

In this prospective randomized study the statistically significant differences in femoral component rotation using the techniques mentioned above as well as differences in individual knee desaxations were observed. The rotations are shown in the figures $2-7$. In patients with neutral limb axis (19 knees) the average CTA value is 3.5 degrees and LBA value is 3.42 degrees. CTA value is the same as LBA in 10 knees (52.63\%), lower in 3 knees (15.78\%), and higher than LBA in 6 knees (31.57\%), approximately about 1-2 degrees. In patients with varus desaxation ( 22 knees) the average CTA value is 2.27 degrees and LBA value is 1.05 degrees. There is not any case in which LBA is higher than CTA. The average CTA value in patients with valgus desaxation ( $9 \mathrm{knees}$ ) is 4.78 degrees and LBA value is 5.22 degrees. CTA equals LBA in 4 knees (44.44\%), LBA is higher than CTA in 4 knees (44.44\%), and LBA is lower than CTA only in one knee (11.11\%). According to Tukey Post Hoc test a statistically significant difference in LBA value is between neutral and varus knees with a significance level of $p=0.000022$, and the most significant difference between varus and valgus knees with a significance level of $p=0.000011$ (Figs. 2-7). 


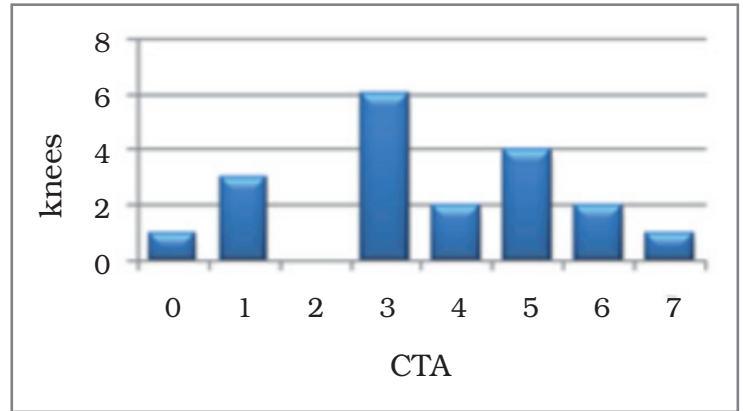

Fig. 2 CTA in normal knees, degrees of CTA vs. amount of the knees

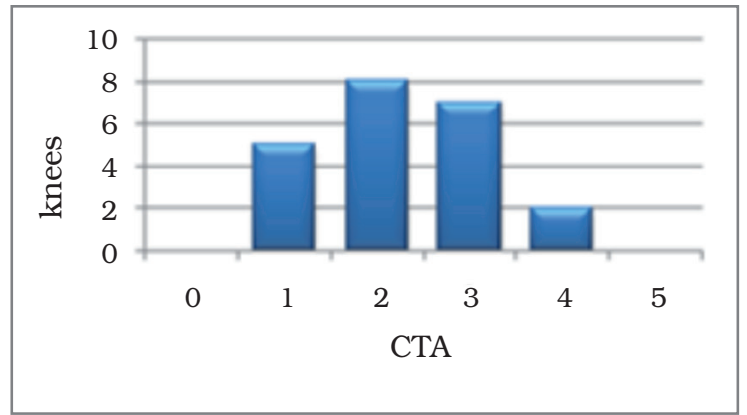

Fig. 4 CTA in varus knees, degrees of CTA vs. amount of the knees

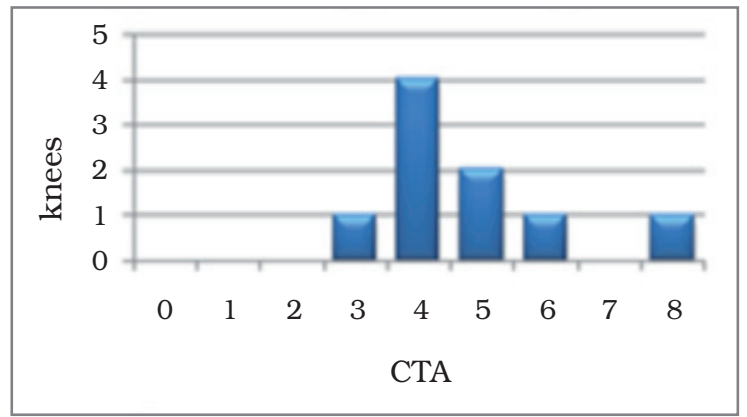

Fig. 6 CTA in valgus knees, degrees of CTA vs. amount of the knees

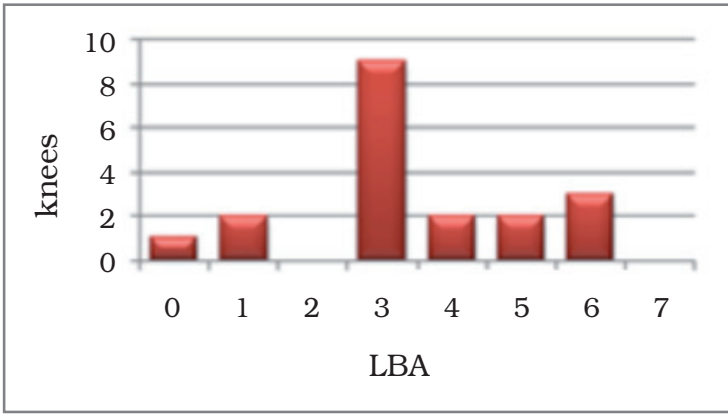

Fig. 3 LBA in normal knees, degrees of LBA vs. amount of the knees

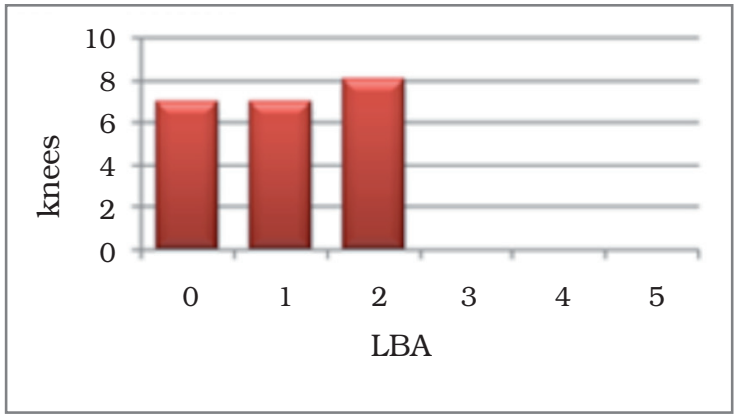

Fig. 5 LBA in varus knees, degrees of LBA vs. amount of the knees

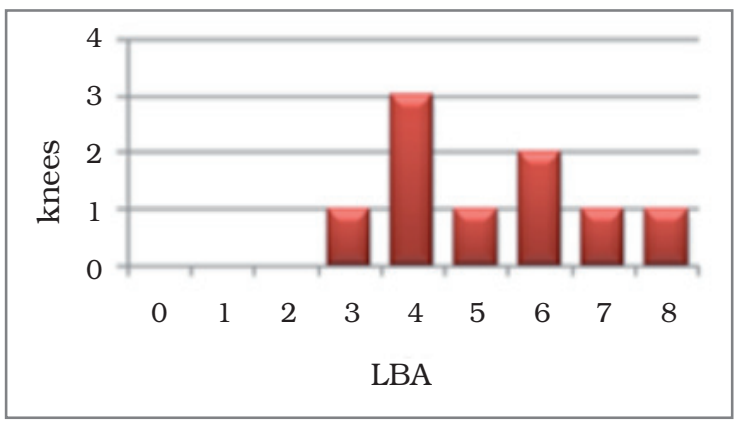

Fig. 7 LBA in valgus knees, degrees of LBA vs. amount of the knees

\section{DISCUSSION}

Reaching a symmetric balanced flection and extension gap is a goal of each total knee arthroplasty (16). Precise balance of the soft tissues with accurate bone resections determine femoral component rotation (10). Incorrect femoral component rotation leads to patellofemoral instability (5), pain in the anterior part of the knee, arthrofibrosis (17), and flection instability (18). To determine femoral component rotation, transepicondylar axis, 
Whiteside line, posterior femoral condyles axis, and balanced flection gap method are commonly used (13).

Balanced gap technique is based on symmetric tone of stabilising structures in the medial and lateral compartment regardless bone reference with symmetric flection gap due to parallelity of resections of the posterior femoral condyles and proximal tibia $(6,19,20)$.

Accurate resection of the proximal tibia is neccessary for the balanced gap technique. Varus tibial resection leads to intrarotation of the femoral component. On the other hand, valgus tibial resection results in extrarotational position. Krackow and Mihalko reported that soft tissue release in extension affects also the flection gap (14). It means that medial soft tissue release in varus knees can lead to excessive extrarotation of distal femur by applying ligament balacer in flection and intrarotation of femoral component to transepicondylar line. On the other hand, in valgus desaxation with lateral soft tissue release we assume intrarotation of the distal femur with extrarotation of the femoral component to transepicondyle axis $(13,15)$.

In the case of bone landmarks technique, femoral component rotation is determined by transepicondyle axis $(21,22)$, Witheside line $(22)$, and posterior condylar femur axis $(23,24)$. In contrast to balanced gap method the bone resections are performed first regardless to soft tissue and flection gap symmetry (25).

The question of accurate femoral component position is controversial and widely discussed. The method of bone landmarks or balanced gap method has been preferred by some surgeons.

Olcott et al.reached flection gap symmetry in $90 \%$ cases, determined the femoral component rotation by transepicondylar line, in $83 \%$ cases by Whiteside line, and in $70 \%$ cases by the posterior condylar femur axis (26). However, the drawback of the bone landmarks method is difficult peroperative identification of the medial and lateral femoral epicondyle (22).

Various authors reviewed low interindividual and intraindividual accuracy of determination of the transepicondyle axis $(27,28,29,30)$.

However some authors reviewed comparable succession rate of peroperative epicondyles identification with preoperative CT (31). Yau et al. found 56\% error rate higher than 5 degrees in determination of femoral component rotation by means of the transepicondylar line caused by wrong peroperative indetification of the epicondyles (32). Benjamin et al. found out the accuracy of determining by means of the transepicondylar axis only in $34 \%$ (33).

The relation between the transepicondylar line and posterior femoral condyles axis was described by Griffin et al. (34). According to him the average angle between both lines was 3.7 degrees. However, the angle was lower in varus desaxation and higher in valgus desaxation. Arima and Whiteside deny the accuracy of the transepicondylar axis in determination of femoral component rotation because the angles between the transepicondylar axis and posterior femoral condyles axis ranged from -4.5 to 15.5 degrees (35).

There are different opinions on the relation of the transepicondylar axis method and rotation determined by balanced gap technique. Some authors reviewed comparable reliability of both methods in determining the correct femoral component rotation $(36,37)$ while others found significant discrepancy. Matziolis et al. found that the femoral component rotation in balanced knees is in a range from 7 degrees of intrarotation to 6 degrees of extrarotation in relation to transepicondylar axis [38]. Heesterbeek et al. confirmed the individual variability of the femoral component rotation and variation depending on soft tissues balancing from 7 degrees of intrarotation to 13 degrees of extrarotation (15).

Katz et al. compared the transepicondylar axis, Whiteside line, and balancer technique for rotation determining (39). He found that transepicondylar axis was more extrarotated than Whiteside line and rotation of balanced gap technique. Regarding its independence on bony landmarks the balanced gap technique is more reliable than transepicondylar axis and Whiteside line. 
Also, Shrinad et al. found higher extrarotation of the transepicondylar axis than balanced gap technique rotation, approximately 3 degrees (40).

Laskin et al.found the difference of approximately 3 degrees between balanced gap technique axis and posterior condylar axis in non-desaxated and varus knees. But the difference increased in valgus knees up to 10 degrees (16). In contrast, Fehring et al. found the difference in angle measurement of the axes varies from -7 to +8 degrees (6). In $45 \%$ of cases the difference was higher than 3 degrees.

The cases with intrarotation position of the femoral component remain unsolved. Most of the authors $(1,5,8,41)$ talk about negative influence of the intrarotation of the femoral component on patellar tracking and the anterior knee pain. But there are also authors who deny this (42).

It is important to differ the intrarotation of the femoral component when ligament balancer and bony landmarks are being used. In case of ligament balancer the component intrarotation in relation to the transepicondylar axis is caused by extrarotation of the distal femur by ligamentous structures tonisation in flection. The component intrarotation is only relative as the flection gap is symmetric. More serious issue is component intrarotation in relation to the transepicondylar axis caused by inaccurate identification of epicondyles leading to asymmetric flection gap. In this case it is absolute intrarotation with consequencies on the patellar tracking.

Some authors reviewed intrarotational tibial component malposition as the most negative impact on the anterior knee pain $(43,44)$. Tibial component intrarotation leads to extrarotation of the tuberositas tibiae resulting in $\mathrm{Q}$ angle increase and negative impact on patellar tracking.

In our study the hypothesis of rotation variability of the femoral component by means of balanced gap technique and transepicondylar axis as well as the dependence of the relation on the pre-operational knee desaxation was confirmed. The femoral component extrarotation ranged from 0-8 degrees in relation to the dorsal femoral condyles line by use of balanced gap technique. The deviation in rotation from the transepicondylar axis was not assessed as malposition. In determination of femoral component rotation an individual approach is preferred because we do not consider only bony landmarks technique as reliable.

The drawback of the study is a relatively small amount of the participants, especially the patients with valgus desaxation. The reason is a duration of the study as well as one surgeon involved in order to ensure the same surgical skills.

\section{CONCLUSION}

Nowadays implantation of the knee joint is continually increasing and becomes more common also in younger patients. For this reason the implant durability should be as long as possible and it depends mostly on correct prosthesis position. The most controversial issue is femoral component rotation and balance of the knee soft tissue. In this study a statistically significant difference in femoral component rotation by use of different methods of implantation as well as a difference in particular knee desaxation was observed. In our department we prefer using balanced gap technique because symmetry of extension and flection gap is our priority. In our opinion the symmetric tonus of stabilizing structures and reaching this symmetry by means of transepicondylar line or other bone references is not reliable in some cases. 


\section{REFERENCES}

1) Anouchi Y, Whiteside L, Kaiser A, Milliano M 1993. The effects of axial rotational alignment of the femoral component on knee stability and patellar tracking in total knee arthroplasty demonstrated on autopsy specimens. Clin Orthop Relat Res, 1993. 287:170-177.

2) Insall J, et al. Surgery of the knee.2nd ed. New York, Churchill Livingston, 1993.

3) Moreland J.Mechanisms of failure in total knee arthroplasty. Clin Orthop Relat Res. 1988;226:49-64.

4) Barrack R, Schrader T, Bertot A, Wolfe M, Myers L.Component rotation and anterior knee pain after total knee arthroplasty. Clin Orthop Relat Res. 2001;392:46-55.

5) Berger R, Crossett L, Jacobs J, Rubash H. Malrotation causing patellofemoral complications after total knee arthroplasty.Clin Orthop, 1998. 356:144-53.

8) Fehrling T. Rotational malalignment of the femoral component in total knee arthroplasty. Clin Orthop Relat Res. 2000;380:72-9.

7) Insall J, Scuderi G, Komistek R, Math K, Dennis D, Anderson D. Correlation between condylar lift-off and femoral component alignment. Clin Orthop Relat Res. 2002;403:143-52.

8) Matsuda S, Miura H, Nagamine R, Urabe K, Hirata G, Iwamoto Y. Effect of femoral and tibial component position on patellar tracking following total knee arthroplasty: 10-year followup of MillerGalante I knees. Am J Knee Surg. 2001;14:152-6.

9) Romero J, Stähelin T, Wyss T, Hofmann S. Significance of axial rotation alignment of components of knee prostheses. Orthopade. 2003;32:461-8.

10) Scuderi G, Komistek R, Dennis D, Insall J. The impact of femoral component rotational alignment on condylar lift-off. Clin Orthop Relat Res. 2003; 410:148-54.

11) Ranawat C. The patellofemoral joint in total condylar knee arthroplasty: pros and cons based on 5- to 10-year follow-up observations. Clin Orthop Relat Res. 1986;205:93.

12) Stiehl J, Komistek R, Dennis D a kol. Flouroscopic analysis of kinematics after posterior-cruciate-retaining knee arthroplasty.J Boint Joint Surg, 1995. 77-B:884-889.

13) Scott RD.Femoral and tibial component rotation in total knee arthroplasty. Bone Joint J. 2013;95B, 140-3.

14) Krackow K, Mihalko W. The effect of medial release on flexion and extension gaps in cadaveric knees: implications for soft-tissue balancing in total knee arthroplasty. Am J Knee Surg. 1999;12:222-228.

15) Petra JC Heesterbeek, MSc, Wilco CH Jacobs, MSc, Ate B Wymenga, MD, PhD. Effects of the Balanced Gap Technique on Femoral Component Rotation in TKA.Clin Orthop Relat Res. 2009;467(4):1015-1022.

16) Laskin R. Flexion space configuration in total knee arthroplasty. Arthroplasty, 1995. s. 657-660.

17) Boldt JG, Stiehl JB, Holder J, Zanetti M, Munzinger J. Femoral component rotation and arthrofibrosis following mobile-bearing total knee arthroplasty. Int Orthop, 2006. 30(5):420-425.

18) Incavo SJ, Wild JJ, Coughlin KM, Beynonn BD. Early revision for component malrotation in total knee arthroplasty. Clin Orthop Relat Res, 2007. 458:131-136.

19) Insall J, Scott W. Insall \& Scott surgery of the knee. 4th edition. Philadelphia: Church Livingstone/Elsevier, 2006.

20) Dennis D. Measured resection: an outdated technique in total knee arthroplasty.Orthopedics. 2008; 31(9):940, 943-4.

21) Berger R, Rubash H, Seel M, Thompson W., Crossett L. 1993. Determining the rotational alignment of the femoral component in total knee arthroplasty using the epicondylar axis. Clin Orthop Relat Res., 1993. (286):40-47.

22) Griffin F, Math K, Scuderi G, Insall J, Poilvache P. 2000. Anatomy of the epicondyles of the distal femur: MRI analysis of normal knees. J Arthroplasty, 2000. 15(3):354-359.

23) Mantas J, Bloebaum R, Hofmann A. Implications of reference axes used for rotational alignment of the femoral component in primary and revision knee arthroplasty. J Arthroplasty, 1992. 7(4):531-535. 
24) Schnurr C, Nessler J, Konig D. Is referencing the posterior condyles sufficient to achieve a rectangular flexion gap in total knee arthroplasty? Int Orthop, 2009. 33(6):1561-1565.

25) Lotke P, Lonner J. Knee arthroplasty. 3rd ed. Philadelphia, PA: Wolters Kluwer Health/Lippincott Williams \& Wilkins, 2009.

26) Olcott C, Scott R. A comparison of 4 intraoperative methods to determine femoral component rotation during total knee arthroplasty. J Arthroplasty, 2000. 15(1):22-26.

27) Yan C, Yau W, Ng T, Lie W, Chiu K, Tang W. Inter- and intra-observer errors in identifying the transepicondylar axis and Whiteside's line. J Orthop Surg (Hong Kong) 2008;16:316-20.

28) Yoshino N, Takai S, Ohtsuki Y, Hirasawa Y. Computed tomography measurement of the surgical and clinical transepicondylar axis of the distal femur in osteoarthritic knees. J Arthroplasty. 2001;16:493-497.

29) Winemaker M. Perfect balance in total knee arthroplasty: The elusive compromise. J Arthroplasty. 2002;17:2-10.

30) Geiger F, Parsch D Intraoperative assessmentf femoral component rotational alignment in total knee arthroplasty. Arch Orthop Trauma Surg. 2008;128(3):267-70.

31) Koudela K Jr., Koudelová J, Koudela K Sr., Kormunda S,KřenJ,Pokorný J. Komparace a statistické zhodnocení dvou metod měření "condylar twist angle" u aloplastiky kolenního kloubu. Acta chirurgiae orthopaedicae et traumatologiae čechoslovaca 79. 2012; p. $324-330$.

32) Yau W, Chiu K, Tang W. How precise is the determination of rotational alignment of the femoral prosthesis in total knee arthroplasty: an in vivo study. J Arthroplasty, 2007. 22(7):1042-1048.

33) Benjamin J. Determining femoral component position using CAS and measured resection. Clin Orthop Relat Res., 2008. 466(11):2745-2750.

34) Griffin F, Insall J, Scuderi G. The posterior condylar angle in osteoarthritic knees. J Arthroplasty, 1998. 13 pp. 812-815.

35) Arima J, Whiteside L, McCarthy D, a kol. Femoral rotational alignment, based on anteroposterior axis, in total knee arthroplasty in valgus knee.J Bone Joint Surg, 1995. 77A: 1331-1334.

36) Luyckx T, Peeters T, Vandenneucker H, Victor J, Bellemans J. Is adapted measured resection superior to gap balancing in determining femoral component rotation in total knee replacement? J Bone Joint Surg Br. 2012 Sep;94(9):1271-6.

37) Nikolaides A, Kenanidis E, Papavasiliou K, Sayegh F, Tsitouridis I, Kapetanos G. Measured resection versus gap balancing technique for femoral rotational alignment: a prospective study.J Orthop Surg (Hong Kong). 2014 Aug;22(2):158-62.

38) Matziolis G, Boenicke H, Pfiel S, Wassilew G, Perka C. The gap technique does not rotate the femur parallel to the epicondylar axis.Arch Orthop Trauma Surg. 2011 Feb;131(2):163-6.

39) Katz M, Beck T, Silber J, Lotke P, Selber J. Determining femoral rotational alignment in total knee arthroplasty: reliability of techniques. J Arthroplasty, 2001. 16(3):301-305.

40) Vaidya S, Gadhiya R, Bagaria V, Ranawat A, Ranawat C. Computed tomographic evaluation of femoral component rotation in total knee arthroplasty.Indian J Orthop. 2013 Jan-Feb; 47(1): 40-44.

41) Rhoads D, Noble P, Reuben J, Mahoney O, Tullos H. The effect of femoral component position on patellar tracking after total knee arthroplasty. Clin Orthop Relat Res, 1990. 260:43-51.

42) Rienmüller A,Guggi T, Gruber G, Preiss S, Drobny T. The effect of femoral component rotation on the five-year outcome of cemented mobile bearing total knee arthroplasty.Int Orthop. 2012 Oct; 36(10): 2067-2072.

43) Nakahara H, Okazaki K, Hamai S, Kawahara S, Higaki H, Mizu-uchi H, Iwamoto Y. Rotational alignment of the tibial component affects the kinematic rotation of a weight-bearing knee after total knee arthroplasty.Knee. 2015 Jun;22(3):201-5.

44) Nicoll D, Rowley D. Internal rotational error of the tibial component is a major cause of pain after total knee replacement.J Bone Joint Surg Br. 2010 Sep;92(9):1238-44.

Received: September, 25, 2017

Accepted: December, 1, 2017 